\title{
Analisis Banjir Rancangan dengan Mempertimbangkan Karakteristik Fraktal Daerah Aliran Sungai (Studi Kasus: Bendungan Way Apu di Pulau Buru, Provinsi Maluku)
}

\author{
Mohamad Bagus Ansori ${ }^{1}$, I Gede Tunas ${ }^{2}$, dan Nastasia Festy Margini ${ }^{1}$ \\ Institut Teknologi Sepuluh Nopember (ITS) ${ }^{1}$, Universitas Tadulako ${ }^{2}$ \\ Jl. Arief Rahman Hakim, Surabaya 60111 Indonesia \\ e-mail: bagus.ansori@ce.its.ac.id
}

\begin{abstract}
Abstrak- Penelitian ini menyajikan permodelan matematika untuk mensimulasikan banjir rancangan pada bendungan Way Apu dengan mempertimbangkan karakteristik fraktal dari DAS. Bendungan Way Apu yang terletak di Sungai Way Apu, Maluku, Indonesia di bangun sebagai bendungan multiguna seperti irigasi, pembangkit listrik tenaga air (PLTA), air baku, dan untuk pengendali banjir sebagai tujuan utama. Analisa banjir rancangan pada bendungan ini mendapatkan beberapa kendala karena besarnya curah hujan di wilayah timur Indonesia, terutama di Pulau Buru Provinsi Maluku. Desain banjir untuk Dam tipe urugan di bawah $40 \mathrm{~m}$ di Indonesia mengacu pada SNI-34321994, menggunakan kemungkinan banjir maksimum periode ulang 1000 tahun untuk perencanaan risiko besar. Makalah ini akan menganalisis desain banjir Bendungan Way Apu dengan periode ulang 1000 tahun dengan mempertimbangkan karakteristik fraktal dari DAS menggunakan hidrograf sintetik ITS-2. Hasil perhitungan menggunakan HSS ITS-2 diperoleh nilai banjir rancangan sebesar $2454,15 \mathrm{~m}^{3} / \mathrm{dt}$. Perhitungan penelusuran banjir (flood routing) diperoleh penurunan debit outflow sebesar 3,65\% dengan Panjang pelimpah (spillway) $60 \mathrm{~m}$, dengan elevasi mercu pada elevasi +134 .
\end{abstract}

Kata Kunci-Banjir Rancangan, Bendungan Urugan, Fraktal, Hidrograf, ITS-2

\section{PENDAHULUAN}

Sungai Way Apu sebagai salah satu sungai terpanjang di Pulau Buru (panjang sungai $47,25 \mathrm{~km}$ dan luas DAS 457,10 $\mathrm{km}^{2}$ ) memiliki permasalahan tahunan yaitu kejadian banjir pada setiap musim hujan. Debit banjir tahunan yang terjadi selalu lebih besar dari kapasitas eksisting dari Sungai Way apu. Untuk itu pada sungai ini direncanakan pembangunan Bendungan Way Apu sebagai infrastruktur pengendali banjir sebagai tujuan utama. Sebagai bendungan multi guna, Bendungan Way Apu juga diharapkan akan memenuhi kebutuhan air baku, air irigasi, dan PLTA. Pembangunan Bendungan Way Apu rencananya dilaksanakan melalui paket kontrak hingga tahun 2022 (4 tahun). Bendungan tersebut akan memiliki volume tampung efektif 30 juta meter kubik yang dapat mengairi lahan irigasi seluas 5.000 ha, untuk air baku 60 liter/detik pada jam puncak, dan listrik sebesar 8 megawatt.

Pulau Buru sebagai salah satu pulau terbesar di Kepulauan Maluku (Gambar 1), memiliki luas $8.473,2 \mathrm{~km}^{2}$, dan panjang garis pantai 427,2 km. Pulau Buru memiliki 9 kecamatan yaitu Waplau, Batabual, Namlea, Air Buaya, dan Waeapo, Madan, Leksula, Namrole, Waisama, Batabual.. Kecamatan Waeapo memiliki jumlah penduduk 16.368 jiwa terpadat kedua setelah Kecamatan Namlea. Sebagian besar penduduk Way Apu berempat tinggal di dataran rendah sepanjang pantai dan pada lembah sungai Way Apu. Sehingga dengan dibangunnya bendungan Way Apu, akan meminimalisir dampak negatif dan kerugian pada masyarakat yang tinggal di daerah sekitar sungai Way Apu. Selain itu, dengan potensi debit dan tampungan dari bendungan Way Apu, akan berdampak pada tercukupinya kebutuhan irigasi untuk kebutuhan pertanian sehingga di dapatkan kenaikan hasil pertanian di Pulau Buru, 
karena selama ini, pemenuhan kebutuhan air irigasi selalu tidak mencukupi pada musim kemarau.

Dari data teknis perencanaan bendungan Way Apu dan redesain bendungan Way Apu [1] di dapatkan nilai banjir rancangan yang besar yaitu $5816 \mathrm{~m} 3 / \mathrm{s}$, dari desain Probability Maximum Flood (PMF) metode HSS Nakayasu. Dari nilai banjir rancangan tersebut diperoleh desain spillway/pelimpah menjadi sangat panjang yaitu $200 \mathrm{~m}$. di dalam SNI3432-1994, disebutkan bahwa untuk bendungan tipe urugan dengan tinggi kurang dari 40 meter, cukup di desain dengan analisis banjir dengan periode ulang 1000 tahun. Sehingga dalam makalah ini akan mengambil desain tersebut dan tidak mempertimbangkan nilai debit Probability Maximum Flood $(P M F)$ untuk analisis banjir rancangannya.

Pada tahun 2017, [2] telah melakukan studi tentang HSS ITS 2 yang mempertimbangkan fraktal karakteristik DAS. HSS ITS 2 diteliti pada 8 DAS di daerah Sulawesi Tengah, dimana cukup dekat dengan Pulau Buru dan dimungkinkan memiliki kemiripan pola hujan yaitu pola hujan pada daerah Indonesia Timur. Oleh karena itu, dalam penelitian ini akan dilakukan analisis banjir rancangan (flood design) dengan mempertimbangkan fractal karakteristik dari DAS untuk studi pada Bendungan Way Apu di Pulau Buru, Provinsi Maluku Indonesia.

\section{METODE PENELITIAN}

Metode penelitian mengadopsi studi yang telah dilakukan oleh [2], [3], [4], [5], [6], [7] dan [8] dengan mengacu pada peraturan [9]. Sistematika metodologi penelitian apabila dibuat dalam diagram alir (flow chart), dapat dilihat pada gambar 1 berikut ini.

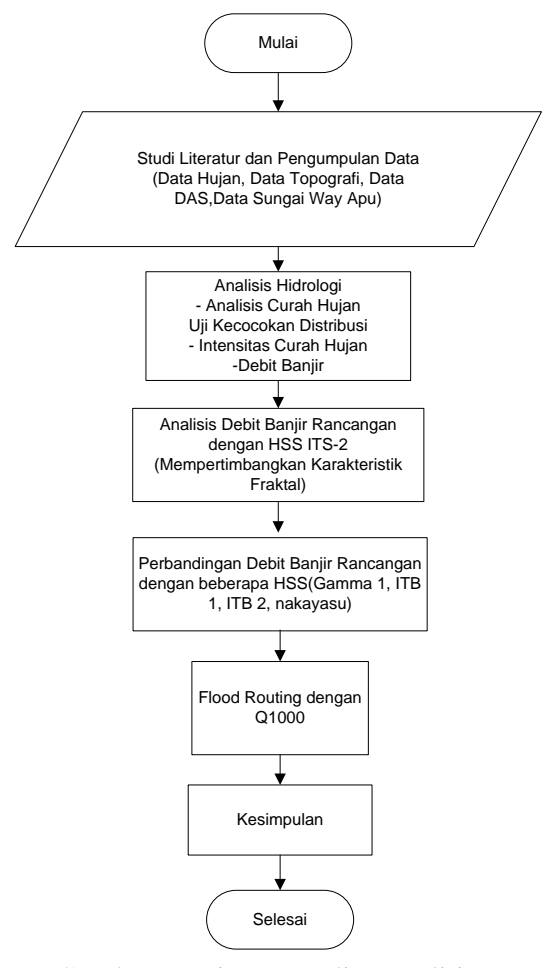

Gambar 1. Diagram Alir Penelitian.

a. Pemilihan Kala Ulang untuk Perencanaan Bendungan

Pemilihan kala ulang untuk perencanaan bendungan urugan di Indonesia diatur dalam SNI-3432-1994 [9]. Perhitungan banjir rancangan yang diatur adalah dengan metode hidrogtaf satuan. Secara garis besar, perhitungan debit banjir desain terdiri dari tiga tahap yaitu perhitungan curah hujan desain, perhitungan debit banjir desain, dan pengujian hasil perhitungan debit banjir desain. Patokan banjir desain dan kapasitas pelimpah untuk Bendungan sesuai [9] sesuai tabel 1 berikut.

Tabel 1. Patokan Banjir Desain dan Kapasitas Pelimpah untuk Bendungan

\begin{tabular}{|c|c|c|c|c|}
\hline \multirow{2}{*}{$\begin{array}{c}\text { Jenis dan } \\
\text { Kelas } \\
\text { Bendungan }\end{array}$} & \multicolumn{2}{|c|}{$\overline{~ K o n s e k u e n s i ~ B e s a r ~}$} & \multicolumn{2}{|c|}{ "Konsekuensi Kecil } \\
\hline & Banjir desain & Kapasitas Pelimpah & $\begin{array}{l}\text { Banjir } \\
\text { desain }\end{array}$ & $\begin{array}{l}\text { Kapasitas } \\
\text { Pelimpah }\end{array}$ \\
\hline \multirow[t]{2}{*}{$\begin{array}{l}\text { 1. } \begin{array}{l}\text { Bendunga } \\
\text { n Urugan }\end{array} \\
\begin{array}{l}\text { (1) }<40 \mathrm{~m} \\
\text { (rendah) }\end{array}\end{array}$} & $\begin{array}{l}\text { Q } 1000 \text { dan } \\
\text { PMF (Probability } \\
\text { Maximum Flood) }\end{array}$ & $\begin{array}{c}\text { Ditentukan } \\
\text { dengan penelusuran } \\
\text { banjir }\end{array}$ & $\begin{array}{r}\text { Pilih } \\
\text { terbesar } \\
\text { antara Q } \\
1000 \text { dan } \\
0,5 \mathrm{PMF}\end{array}$ & $\begin{array}{c}\text { Ditentukan } \\
\text { dengan penelusuran } \\
\text { banjir }\end{array}$ \\
\hline & & $\begin{array}{c}\text { Minimal 15\% } \\
\text { debit puncak PMF }\end{array}$ & & $\begin{array}{r}\text { Minimal 15\% } \\
\text { debit puncak PMF }\end{array}$ \\
\hline \multirow[t]{2}{*}{ (2) $\begin{array}{l}40-80 \mathrm{~m} \\
\text { (sedang) }\end{array}$} & sda & $\begin{array}{c}\text { Ditentukan } \\
\text { dengan penelusuran } \\
\text { banjir }\end{array}$ & sda & $\begin{array}{c}\text { Ditentukan } \\
\begin{array}{c}\text { dengan penelusuran } \\
\text { banjir }\end{array} \\
\end{array}$ \\
\hline & & $\begin{array}{r}\text { Minimal 15\% } \\
\text { debit puncak PMF } \\
\end{array}$ & & $\begin{array}{r}\text { Minimal } 25 \% \\
\text { debit puncak PMF }\end{array}$ \\
\hline \multirow[t]{2}{*}{$\begin{array}{ll}\text { (3) } & >80 \mathrm{~m} \\
& \text { (tinggi) }\end{array}$} & sda & $\begin{array}{c}\text { Ditentukan } \\
\text { dengan penelusuran } \\
\text { banjir }\end{array}$ & sda & $\begin{array}{c}\text { Ditentukan } \\
\text { dengan penelusuran } \\
\text { banjir } \\
\end{array}$ \\
\hline & & $\begin{array}{r}\text { Minimal 35\% } \\
\text { debit puncak PMF }\end{array}$ & & $\begin{array}{r}\text { Minimal 35\% } \\
\text { debit puncak PMF }\end{array}$ \\
\hline
\end{tabular}

Sumber: SNI-3432-1994 
JURNAL HIDROTEKNIK Vol. 2, No.2, (2017) ISSN : 2477-3212

\section{b. Hidrograf Satuan Sintetik (HSS) ITS-2}

Model Hidrograf satuan sintetik atau biasa disingkat HSS adalah model transformasi hujan-debit yang disusun berdasarkan teori hidrograf satuan (hidrograf yang dihasilkan oleh hujan satu satuan akibat hujan merata di seluruh DAS dengan durasi tertentu) dengan menggunakan parameter DAS sebagai dasar penyusun model [14]. Gagasan penyusunan dan pemilihan HSS ini didasarkan oleh keterbatasan data hidrologi dan hidrometri, sehingga hidrograf aliran lebih dipresentasikan oleh karakteristik dari DAS itu sendiri [18]. Permasalahan di Indonesia, model HSS seperti HSS Snyder (1938) [19] , Nakayasu (1975) [10][16][17] , GAMMA1 (1985) [12][13][14], GAMMA 2, ITB 1, ITB 2 [11], ITS 1 [14], ITS 2 [2] telah banyak digunakan baik oleh para peneliti maupun para praktisi rekayasa untuk perhitungan debit rancangan.

HSS ITS- 2 dikembangkan di 8 DAS di Sulawesi Tengah dan menunjukkan hasil kinerja yang cukup baik dibandingkan dibandingkan dengan HSS yang lain. Oleh karena itu HSS ITS-2 dipilih dalam penelitian ini karena wilayah pengembangan HSS sangat dekat dengan lokasi penelitian. Diharapkan hasil Analisa yang diperoleh akan mewakili dan mendapatkan hasil yang paling mendekati.

Parameter model HSS ITS-2 dianalisis menggunakan regresi linear berganda berdasarkan hubungan antara parameter hidrograf dengan parameter fractal dan morfometri DAS. Analisis regresi menghasilkan persamaan waktu puncak (Tp) sebagai fungsi dari parameter panjang sungai utama (L), rasio panjang sungai (Rl) dan kerapatan jaringan drainase (D) dengan koefisien determinasi $\left(\mathrm{r}^{2}\right)$ 99,9\%. Persamaan waktu dasar ( $\mathrm{Tb}$ ) sebagai fungsi dari luas DAS (A) dan kemiringan sungai utama (S) dengan koefisien determinasi $\left(\mathrm{r}^{2}\right) 98,7 \%$. Persamaan debit puncak sebagai fungsi dari waktu puncak (Tp) dan Luas DAS (A). Selain itu HSS ITS 2 telah merumuskan persamaan kurva tunggal yang lebih sederhana dan dapat mengatasi kelemahan dan keterbatasan persamaan kurva tunggal HSS lainnya. Persamaan kurva tunggal ini diturunkan dari Persamaan distribusi Gamma yang merupakan bagian dari distribusi probabilitas kontinyu dua parameter (2PGDF).

Bentuk persamaan akhir dari ketiga parameter utama HSS ITS-2 meliputi Tp, Tb, dan Qp adalah seperti bersamaan 2.1-2.3 berikut. Dimana untuk persamaan Tp dan Tb dikalikan dengan suatu koefisien yang akan digunakan untuk mengkalibrasi model. Apabila kalibrasi tidak dapat dilakukan akibat data pengamatan tidak tersedia, maka koefisien tersebut dapat ditetapkan $=1$.

$$
\begin{aligned}
& T p=C 1(0.102 L-0.162 D-0.524 R l+1.24) \\
& T b=C 2(0.136 A-43.0 S+11.5) \\
& \mathrm{Qp}=\frac{R 0}{3.6 T p} \times \frac{A}{A h s S} \\
& \mathrm{q}(\mathrm{t})=\left\{\left(\frac{T}{T p}\right) \exp \left(1-\frac{T}{T p}\right)\right\}^{C 3}
\end{aligned}
$$

C1 adalah koefisien waktu puncak, C2 adalah koefisien waktu dasar dan C3 adalah koefisien yang bersesuaian dengan faktor bentuk hidrograf. Sebagai kelanjutan dari HSS ITS- 1 yang dikembangkan oleh Lasidi (2003) di Institut Teknologi Sepuluh Nopember Surabaya, HSS ITS-2 yang dikembangkan dari kombinasi karakteristik fractal dan morfometri DAS di kembangkan oleh Tunas dkk (2017) [2][3][4] [5][6][7] dan [8].

\section{HASIL DAN DISKUSI}

Analisis banjir rancangan dengan mempertimbangkan karakteristik fractal DAS, terlebih dahulu mengidentifikasi beberapa parameter, diantaranya Panjang sungai utama (L) yaitu diperoleh data 47,22 $\mathrm{km}$, dan panjang sungai pada semua tingkat $=$ 266,62 km. Luas Das (A) Sungai Way Apu sebesr $457,10 \mathrm{~km}^{2}$ sesuai pada gambar 2 . Perhitungan HSS ITS-2 selanjutnya mempertimbangkan fungsi kerapatan jaringan 
JURNAL HIDROTEKNIK Vol. 2, No.2, (2017) ISSN : 2477-3212

drainase (D) yang merupakan rasio luas DAS dan panjang sungai pada semua tingkat. Kerapatan Jaringan drainase untuk Sungai Way Apu diperoleh nilai 0.58. Kemiringan Sungai Utama $(s)=0.01535$. Rasio Panjang sungai (RL) merupakan perbandingan Panjang sungai orde 1 dengan orde tingkat 2 diperoleh nilai 1.13 (Gambar 3).
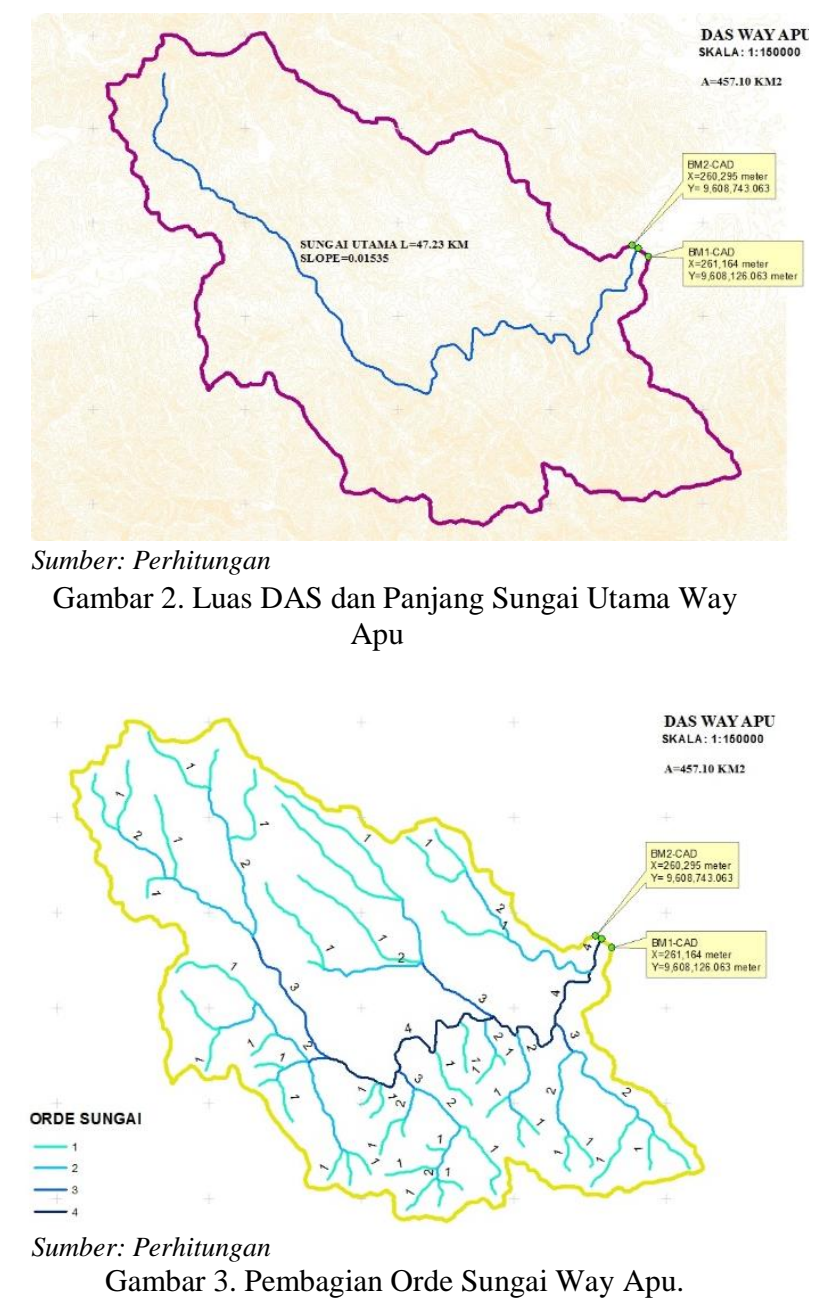

Dari perameter diatas, selanjutnya dihitung nilai waktu puncak (TP) dari persamaan 1 diatas, diperoleh nilai $\mathrm{TP}=5,37$ jam. Pada HSS ITS 2, koefisien waktu puncak (C1) dan koefisien waktu dasar (C2) adalah 1. Waktu dasar dihitung menggunakan persamaan 2 diperoleh nilai 73,01 jam. Selanjutnya dengan persamaan 3, debit puncak (QP) dapat dihitung, dan diperoleh nilai $=8,74 \mathrm{~m}^{3} / \mathrm{s}$. Besaran nilai debit per waktu (persamaan 4) untuk menyusun HSS ITS-2 kemudian dapat dihitung sesuai pada tabel 2 dan gambar 4 berikut.

Tabel 2. Perhitungan Qp dengan HSS ITS-2

\begin{tabular}{|c|c|c|c|c|c|}
\hline $\mathrm{T}(\mathrm{Jam})$ & $\mathrm{t}=\mathrm{T} / \mathrm{TP}$ & $\mathrm{q}=\mathrm{Q} / \mathrm{QP}$ & A & $\mathrm{Q}\left(\mathrm{m}^{3} / \mathrm{s}\right)$ & $\mathrm{V}\left(\mathrm{m}^{3}\right)$ \\
\hline (1) & (2) & (3) & (4) & (5) & (6) \\
\hline 0 & 0.00 & 0.00 & 0.00 & 0.00 & 0.0 \\
\hline 1 & 0.19 & 0.42 & 0.04 & 3.67 & 6612.5 \\
\hline 2 & 0.37 & 0.70 & 0.10 & 6.10 & 17590.2 \\
\hline 3 & 0.56 & 0.87 & 0.15 & 7.59 & 24646.4 \\
\hline 4 & 0.74 & 0.96 & 0.17 & 8.40 & 28796.8 \\
\hline 5.37 & 1.00 & 1.00 & 0.25 & 8.74 & 42273.2 \\
\hline 6 & 1.12 & 0.99 & 0.12 & 8.69 & 19775.0 \\
\hline 7 & 1.30 & 0.96 & 0.18 & 8.41 & 30777.8 \\
\hline 8 & 1.49 & 0.91 & 0.17 & 7.98 & 29506.8 \\
\hline 9 & 1.68 & 0.85 & 0.16 & 7.45 & 27779.1 \\
\hline 10 & 1.86 & 0.79 & 0.15 & 6.87 & 25786.7 \\
\hline 11 & 2.05 & 0.72 & 0.14 & 6.28 & 23669.2 \\
\hline 12 & 2.23 & 0.65 & 0.13 & 5.68 & 21526.9 \\
\hline 13 & 2.42 & 0.58 & 0.11 & 5.11 & 19429.2 \\
\hline 14 & 2.61 & 0.52 & 0.10 & 4.57 & 17422.8 \\
\hline 15 & 2.79 & 0.46 & 0.09 & 4.06 & 15537.4 \\
\hline 16 & 2.98 & 0.41 & 0.08 & 3.60 & 13789.6 \\
\hline 17 & 3.17 & 0.36 & 0.07 & 3.17 & 12187.2 \\
\hline 18 & 3.35 & 0.32 & 0.06 & 2.79 & 10731.2 \\
\hline 19 & 3.54 & 0.28 & 0.06 & 2.44 & 9418.1 \\
\hline 20 & 3.72 & 0.24 & 0.05 & 2.14 & 8241.5 \\
\hline 21 & 3.91 & 0.21 & 0.04 & 1.86 & 7192.7 \\
\hline 22 & 4.10 & 0.19 & 0.04 & 1.62 & 6262.5 \\
\hline 23 & 4.28 & 0.16 & 0.03 & 1.40 & 5440.7 \\
\hline 24 & 4.47 & 0.14 & 0.03 & 1.22 & 4717.3 \\
\hline 25 & 4.66 & 0.12 & 0.02 & 1.05 & 4082.7 \\
\hline 26 & 4.84 & 0.10 & 0.02 & 0.91 & 3527.6 \\
\hline 27 & 5.03 & 0.09 & 0.02 & 0.78 & 3043.2 \\
\hline 28 & 5.21 & 0.08 & 0.02 & 0.67 & 2621.6 \\
\hline 29 & 5.40 & 0.07 & 0.01 & 0.58 & 2255.4 \\
\hline 30 & 5.59 & 0.06 & 0.01 & 0.50 & 1938.0 \\
\hline 31 & 5.77 & 0.05 & 0.01 & 0.43 & 1663.3 \\
\hline 32 & 5.96 & 0.04 & 0.01 & 0.37 & 1426.0 \\
\hline 33 & 6.15 & 0.04 & 0.01 & 0.31 & 1221.3 \\
\hline 34 & 6.33 & 0.03 & 0.01 & 0.27 & 1045.0 \\
\hline 35 & 6.52 & 0.03 & 0.01 & 0.23 & 893.4 \\
\hline 36 & 6.70 & 0.02 & 0.00 & 0.20 & 763.1 \\
\hline 37 & 6.89 & 0.02 & 0.00 & 0.17 & 651.3 \\
\hline 38 & 7.08 & 0.02 & 0.00 & 0.14 & 555.5 \\
\hline
\end{tabular}


JURNAL HIDROTEKNIK Vol. 2, No.2, (2017) ISSN : 2477-3212

$\begin{array}{llllll}39 & 7.26 & 0.01 & 0.00 & 0.12 & 473.4 \\ 40 & 7.45 & 0.01 & 0.00 & 0.10 & 403.2\end{array}$

Sumber: Perhitungan

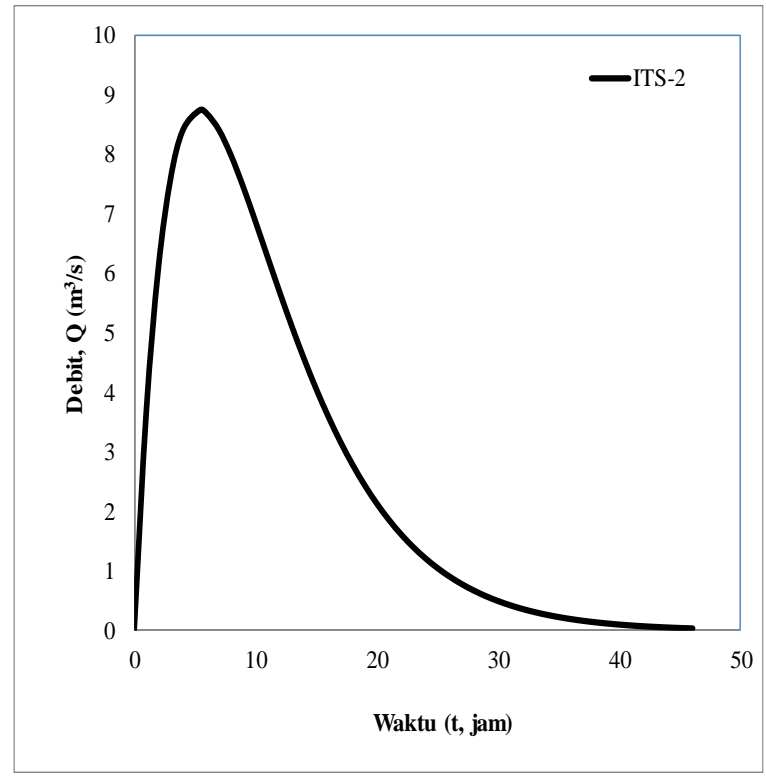

Sumber: Perhitungan

Gambar 4. HSS ITS-2 pada DAS Sungai Way Apu.

Perhitungan debit banjir rancangan dengan periode ulang 1000 tahun diperoleh nilai seperti pada gambar 5. Nilai terbesar adalah HSS Nakayasu sebesar 4079,89 $\mathrm{m}^{3} / \mathrm{dt}$. Perhitungan dengan memperhitungkan karakteristik fraktal menggunakan HSS-ITS 2 diperoleh nilai $2454,15 \mathrm{~m}^{3} / \mathrm{dt}$.

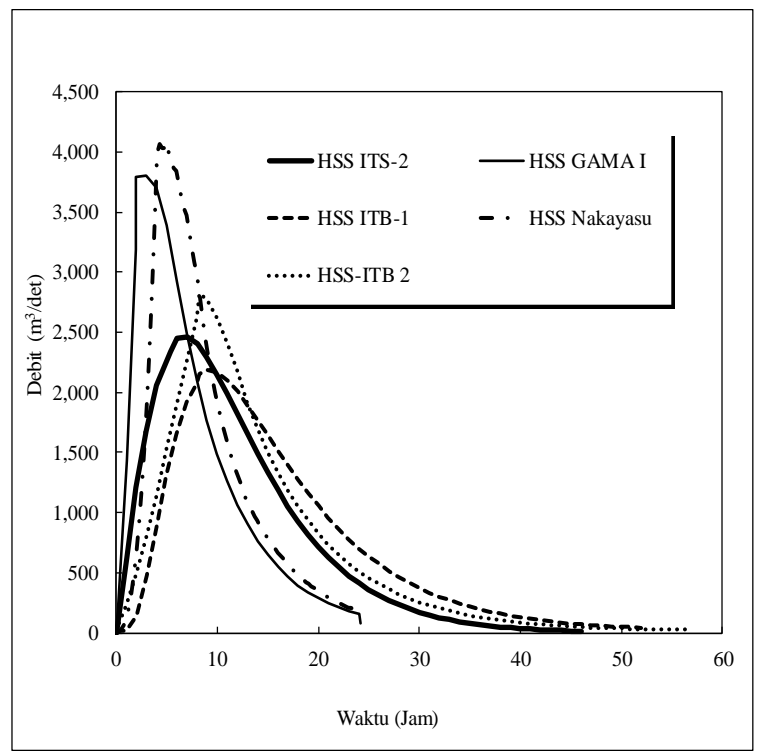

Sumber: Perhitungan

Gambar 5. Perbandingan Debit Rancangan $\mathrm{Q}_{1000}$ pada beberapa HSS.
Penelusuran Banjir Bendungan Way Apu dengan desain banjir rancangan periode ulang 1000 tahun $\left(\mathrm{Q}_{1000}\right)$ menggunakan HSS ITS-2 diperoleh penurunan debit outflow sebesar 3,65\% (Gambar 6) dengan panjang pelimpah $60 \mathrm{~m}$, elevasi pelimpah pada $+134,00$. Tinggi air maksimal di atas pelimpah ketika debit banjir periode ulang 1000 tahun terjadi adalah 6,9 m pada elevasi $+141,90$ dengan tinggi jagaan terhadap puncak tubuh bendungan adalah $1,10 \mathrm{~m}$.

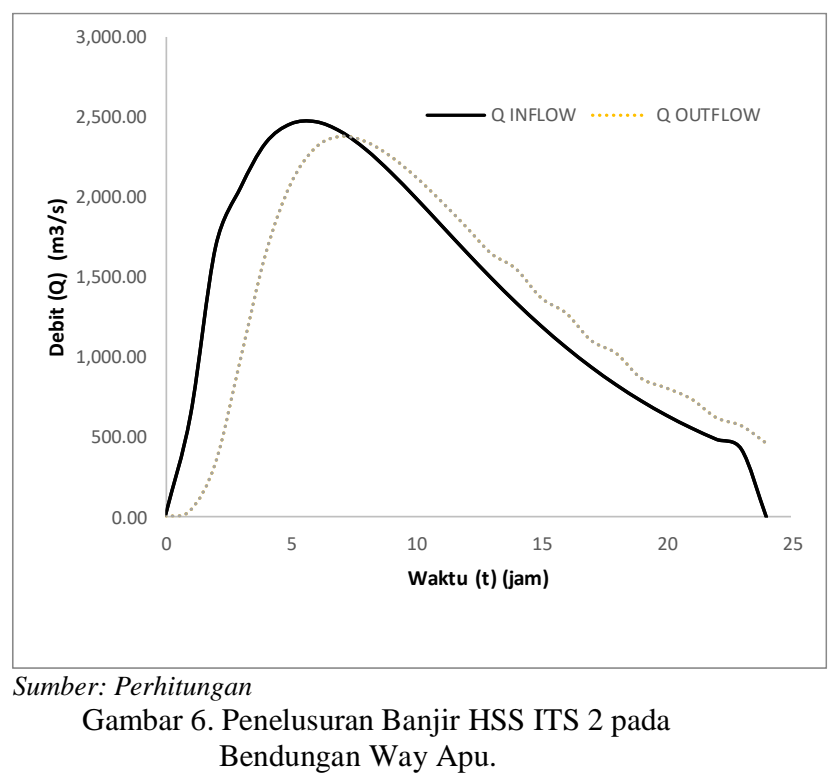

\section{KESIMPULAN/RINGKASAN}

Analisis banjir rancangan pada DAS Way Apu di Pulau Buru diperoleh kesimpulan sebagai berikut.

1. Perhitungan HSS ITS-2 dengan mempertimbangkan karakteristik fractal DAS diperoleh nilai debit puncak sebesar $8,74 \mathrm{~m}^{3} / \mathrm{dt}$, lebih kecil dari pada perhitungan HSS Nakayasu, GAMMA 1, ITB 2.

2. Analisis banjir rancangan dengan periode ulang 1000 tahun $\left(\mathrm{Q}_{1000}\right)$ diperoleh hasi sebesar $2454,15 \mathrm{~m}^{3} / \mathrm{dt}$

3. Penelusuran banjir (flood routing) pada bendungan way Apu dengan menggunakan HSS ITS-2 diperoleh penurunan debit outflow sebesar $3,65 \%$ 
JURNAL HIDROTEKNIK Vol. 2, No.2, (2017) ISSN : 2477-3212

dengan Panjang pelimpah (spillway) 60 $\mathrm{m}$, dengan elevasi mercu pada elevasi +134 .

4. Panjang pelimpah dengan HSS-ITS 2 periode ulang 1000 tahun $\left(\mathrm{Q}_{1000}\right)$ dapat diperkecil secara signifikan dari desain sebelumnya yaitu dari $200 \mathrm{~m}$ menjadi 60 $\mathrm{m}$.

\section{DAFTAR PUSTAKA}

[1] Cahyadi, A. D., Lasminto, U. dan Ansori, M. B. Redesain Bendungan Way Apu Kabupaten Buru Provinsi Maluku. Jurnal Hidroteknik, vol. 1, no. 2 (2015). pp 67-74.

[2] Anwar, Nadjadji., Umboro Lasminto, I Gede Tunas. 2018. Hidrograf Satuan Sintetik ITS2.Surabaya : ITS Press.

[3] Tunas, I. G., Anwar, N.,and Lasminto, U., 2016a, Fractal Characteristic Analysis of Watershed as Variable of Synthetic Unit Hydrograph Model, The Open Civil Engineering Journal (TOCIEJ), Vol. 10, pp. $706-718$.

[4] Tunas, I. G., Anwar, N.,and Lasminto, U., 2016b, Analysis of Dominant Rainfall Distribution Pattern for Flood Hydrograph Prediction , Proceeding of the 3rd International Seminar on Infrastructure Development (ISID) 2016, pp. 43 - 45 .

[5] Tunas, I. G., Anwar, N.,and Lasminto, U., 2016c, Fractal Characteristic Analysis of Watershed Based on Geographical Information System, Proceeding of the 5th International Seminar of HATHI (Indonesian Association of Hydraulic Engineers) 2016, pp. $205-215$.

[6] Tunas, I. G., Anwar, N.,and Lasminto, U., 2017a, Analysis of Main Morphometry Characteristic of Watershed and Its Effect to the Hydrograph Parameters, International Journal for Technology and Science (IPTEK), Vol. 28, No. 1, pp. $30-36$.

[7] Tunas, I. G., Anwar, N.,and Lasminto, U., 2017b, The Improvement of Synthetic Unit Hydrograph Performance by Adjusting Model Parameters for Flood Prediction, International Journal of Engineering and Technology (IJET), Vol. 9, No. 2, pp. $847-858$.

[8] Tunas, I.G., Nadjadji Anwar, Umboro Lasminto. (2015a), Kinerja HSS Snyder, Nakayasu, dan GAMA I Pada DAS terukur di
Sulawesi Tengah, Jurnal Teknik Sumber Daya Air, vol. 1 no. 2 Juni 2015. Himpunan Ahli Teknik Hidraulika Indonesia (HATHI). Hal 105-114

[9] SNI 03-3432-1994 Panduan Perencanaan Bendungan Urugan, Vol. 2 (Analisa Hidrologi), Departemen Pekerjaan Umum (1999, Juli).

[10] Safarina, A. B., 2012, Modified Nakayasu Synthetic Unit Hydrograph Method for Meso Scale Ungauge Watersheds, International Journal of Engineering Research and Applications (IJERA), Vol. 2, No. 4, pp. 649654.

[11] Montarcih, L., 2009, Hidrograf Satuan Syntetic Limantara, Jurnal Rekayasa Sipil, Natakusumah, D.K., Hatmoko, W., dan Harlan, D., 2011, Prosedur Umum Perhitungan Hidrograf Satuan Sintetik dengan Cara ITB dan Beberapa Contoh Penerapannya, Jurnal Teknik Sipil, Vol. 18 No. 3, pp. 251-291.

[12] Soemarto, C. D.,1985, Hidrologi Teknik, Erlangga, Jakarta.

[13] Sri Harto.,2000, Hidrologi : Teori, Masalah dan Penyelesaian, Nafiri Offset, Yogyakarta.

[14] Subramanya, K.,1995, Engineering Hydrology, McGraw Hill, New Delhi.

[15] Triatmojo, B., 2008, Hidrologi Terapan, Beta Offset, Yogyakarta, M. Young, The Techincal Writers Handbook. Mill Valley, CA: University Science (1989).

[16] Margini, N. F., Nusantara, D. A. D., Ansori. M. B. Analisa Hidrograf Satuan Sintetik Nakayasu dan ITB pada Sub Das Konto, Jawa Timur. Jurnal Hidroteknik, vol. 2, no 1 (2017). Pp.

[17] Agus, I. 2007. Modifikasi Persamaan Hidrograf Satuan Sintetis Metoda Nakayasu Terhadap Hidrograf Satuan Observasi DAS Ciliwung Hulu. Rekayasa Sipil.

[18] Lasidi, Edijatno and Anwar, N., (2003) Hidrograf Satuan Sintetik ABG, Prosiding Seminar PIT XX HATHI, 20-21 Oktober.

[19] Nugroho, Sutopo Purwo. 2001. Analisis Hidrograf Satuan Sintetik Metode Snyder, Clark Dan Scs dengan Menggunakan Mode Hec-1 di Das Ciliwung Hulu Jurnal Saint dan Teknologi Modifikasi Cuaca. 